\title{
Situational analysis of the problem of assessing the effectiveness of cluster development of the territory as an aspect of the implementation of its sustainable development
}

Oleg Lyamzin

Novosibirsk State Technical University, K. Marx Avenue, 20, 630073 Novosibirsk, Russia

\begin{abstract}
The development of territorial economic clusters is one of the important conditions for the growth of the competitiveness of economy, for the intensification of public-private partnership instruments and, ultimately, is a significant aspect of ensuring the sustainable development of territories $[1,2,3,4]$. It should be noted that the sustainability of such development is determined, first of all, by the establishment of close integration links both in terms of resources and products generated by the cluster participants. This leads to their joint interest in the overall end result of the cluster, cross-interest in the efficiency of the participants, insurance of the risks of each of them, and a number of other useful economic and social effects [5,6,7]. At the moment, the cluster approach to the intensification of development has taken a prominent place in the relevant concepts and strategies of a number of Russian regions and their municipalities. Today, it can be argued that a set of mechanisms has been formed at the state and regional levels, allowing, for example, to provide flexible financing for measures for the development of clusters $[8,9]$. Nevertheless, the situation is paradoxical when, in the presence of tools, the conceptual and methodological- instrumental part of the solution to the problem of assessing the effectiveness of cluster activities has not yet been sufficiently reflected and developed. This article examines this problem and identifies approaches to overcoming it.
\end{abstract}

\section{Introduction}

One of the significant influencing factors in the framework of the problem situation described above is the lack of attention to the very issue of developing and using adequate approaches to assessing the effectiveness of emerging clusters. The absence of such approaches then leads to the weakness of the evaluation and analytical function of clusters, the resulting lack of understanding of the real effectiveness of their activities and the inevitable problems with the choice and implementation of the cluster directions of their development. In addition, such a circumstance directly affects the activities of administrative and control structures, making it much more difficult to objectively assess the very need, effectiveness and prospects of federal and regional financing of cluster formations. This assessment, when it is based on reporting data on a set of indicators that 
do not adequately disclose the cluster, systemic nature of the object under study, is not able to lead to the formation of sound judgments in the selection of priorities for state financing of cluster development.

\section{Materials and Methods}

Let's consider the current state of affairs with the approaches used to assess the effectiveness of cluster structures in the Russian Federation. Back in 2008, "Methodological recommendations for the implementation of cluster policy in the subjects of the Russian Federation" (N 20615-ak/d19 of 26.12.2008) were developed, which are the main document defining approaches to cluster development at the state and territorial levels [10]. Section 3 of this document states that the main directions of government assistance to the organization and improvement of clusters are " to promote ... the activities of strategic planning of cluster development, the establishment of effective information interaction between the cluster participants and the promotion of strengthening cooperation between them" as well as "the development of mechanisms to support projects aimed at improving the competitiveness of enterprises and promoting the effectiveness of their interaction...". In the same section, it is mentioned that, among others, the main tasks of cluster projects are to improve the quality of management in the organizations participating in the cluster...". The paragraph 3.1 reflects the focus on facilitating the organizational improvement of clusters by various levels of administration through assistance in:

- Formation of cluster strategies and plans for their implementation.

- Organization of information interaction in the cluster between participating organizations.

- Implementation of measures to intensify cooperation between the organizations participating in the integration.

In the paragraph 3.2 of this document, a general definition of mechanisms for strengthening the competitiveness of enterprises and promoting the effectiveness of their interaction is proposed, which is considered as an important point, including in the implementation of cluster initiatives. One of the first mechanisms mentioned in this regard is the mechanism for improving the quality of management in enterprises, which includes: a) assistance in providing management consulting services to enterprises participating in the cluster and b) implementation of systematic activities for benchmarking best practices in the field of management methods and mechanisms in organizations participating in the integration. In paragraph 3.3, one of the significant aspects that hinder the development of Russian technology parks and cluster structures that were previously organized with the participation of universities and state research institutes is the insufficient amount of information and consulting assistance from organizations participating in technology parks and clusters. Section 4 identifies two main vectors of support for the clustering of the economy at the federal level, namely, finalizing the mechanisms for financing cluster structures and organizing access for clustering participants to the required methodological and consulting assistance, as well as assistance in the educational sphere. In the next section, which deals with the risks of improper implementation of the policy of territorial economic clustering and preventive measures, among the most dangerous risks are the risks of incorrect prioritization in subsidies, the risks of improper coordination of work in the implementation of cluster projects and the risks of ineffective monitoring of cluster initiatives.

The most important measures to prevent such risks are the formation of adequate criteria for assessing the effectiveness of clustering and the use of a project - based approach with a focus on a specific result. Further, in the Recommendations, the problems that are overcome in the process of developing different types of clusters include the 
problem of inefficiency in the development of clusters in the organizational aspect, including the weak practice of their strategic planning, the inadequate information communication system within the cluster, the insufficient level of cooperation and subcontracting between the participants.

In general, the analysis of the content of this document suggests that its individual paragraphs reflect a common understanding of the need for clusters to achieve those states that are directly or indirectly related to the success of choosing and formalizing the correct evaluation and analytical approaches and procedures in their activities. At the same time, a full-fledged vision of the primary importance of this issue in the success of the formation and development of clusters in the Russian Federation is obviously not demonstrated there. Over the past years, a certain number of federal and regional regulations and development programs have been adopted to promote the clustering of the economy.

For all the relevance and usually high level of elaboration of this documentation, it should be said that the most common aspects that appear in these documents are usually general directions and approaches to the development of clustering, methodological approaches to identifying and formalizing the cluster status of integrated structures and developing programs for their development, features of competitive selection of applications for inclusion in any of the federal lists of clusters, the specifics of the formation of cluster applications for federal and regional funding, etc. similar aspects. The question of helping cluster participants to choose and use reasonable, adequate and standardized assessment and analytical systems in the Russian Federation, effective in assessing the real effectiveness of participants and the prospects for their development within the cluster (as well as the effectiveness of the clusters themselves), as well as the comparative assessment of clusters among themselves, has not yet been properly understood, reflected, and, accordingly, not resolved. This is confirmed by the analysis of the content of the latest federal programs and projects adopted in the field of cluster development assistance in the Russian Federation. Thus, in Order No. 400 of the Ministry of Economic Development of the Russian Federation (issued on 27.06.2016) "On the priority project of the Ministry of Economic Development of the Russian Federation " Development of innovative clusters-leaders of world-class investment attractiveness"' [11] among the many activities planned as part of its implementation, there was not a single event whose purpose would be directly stated the creation, testing and scaling of the abovedescribed specialized cluster assessment and analytical systems in the Russian Federation. Indirect interest in this problem is reflected only in two points - 3.9 and 14. In paragraph 3.9 , it is reflected that until 07.07.2016 the strategy of this project should be formed, which would include the goals, the most important areas of work and key performance indicators, as well as the main development measures, taking into account the specifics of educational and scientific clusters and organizations of the high-tech sector. In paragraph 14, it is stated that in 2017, the management system for the development of clusters participating in this project should be improved and the effectiveness of such a system should be analyzed. Until 2020 a strategic session should be held to share the experience gained from participating in this project, as well as to obtain best practices for implementation.

Therefore, it can be summarized that once again insufficient attention is shown to one of the most important practical tasks, on the solution of which the success of cluster development in the Russian Federation directly depends. Currently, the assessment of the effectiveness of cluster structures in the regions is most often based on a system of indicators imputed to reporting on them in the implementation of Agreements on subsidies from the federal budget to regional budgets for the implementation of programs for the development of their "pilot" clusters (in the implementation of specific resolutions of the Russian Government and orders of the Ministry of Economic Development of the Russian 
Federation). When monitoring the effectiveness of the provision of state subsidies, the following set of indicators is established:

- The number of employees of the cluster member organizations who have passed professional retraining and advanced training in the programs of additional professional education in the field of innovation management, pers.;

- The increase in the average salary of employees of the participating organizations who have passed professional retraining and advanced training in the programs of additional professional education in the field of innovation management, $\%$;

- Increase in the volume of work and projects in the field of research and development carried out jointly by two or more participating organizations or by one or more participating organizations jointly and foreign organizations, since the beginning of implementation in the reporting financial year and in the next 2 years, $\%$;

- Increase in the volume of investment costs of participating organizations, net of costs for the acquisition of land, construction of buildings and structures, as well as the supply of engineering communications, \%;

- Increase in output per employee of participating organizations, $\%$;

- Growth in the volume of innovative products shipped by participating organizations of their own production, as well as innovative works and services performed on their own, \%;

- Growth of the total revenue of participating organizations from sales of products on the foreign market, $\%$.

The content and quantitative format of the set of indicators, which are used for reporting in order to obtain judgments on the effectiveness of state funding provided to regional budgets to support the development of "pilot" territorial clusters of an innovative nature (presented in the relevant resolutions of the Government of the Russian Federation and orders of the Ministry of Economic Development of the Russian Federation), allows us to highlight the fact that this complex was hardly subjected to a preliminary serious scientific study. Despite the fact that each of these indicators can be used to assess the effectiveness of individual aspects of cluster activity as part of any groupings of indicators, the reasons for the need for their application, and in the proposed set, remain unknown, and the logic that they are intended to translate is unclear. Let's consider the situation on the example of the Novosibirsk region.

The process of monitoring the planned and reported actual indicators provided for in section VI of the Concept of Cluster Policy of the Novosibirsk Region [12] and the Program of State Support for the Development of the Innovative Cluster of Information and Biopharmaceutical Technologies of the Novosibirsk region is carried out today as part of the implementation of specific agreements between federal and regional authorities. In accordance with the Agreements, annual reports are sent to the Ministry of Economic Development of the Russian Federation, which together are designed to reflect the degree of effectiveness of the provision of federal subsidies $[13,14]$. This is a report on the implementation of the values of the efficiency indicators of the allocation of subsidies, a report on the expenditures of the territory's budget, the source of which is recognized as a subsidy, and a report on the implementation of the conditions for the allocation of subsidies. It should be noted that the reporting information is currently being conducted only for one institutionalized innovation cluster of the Novosibirsk region - the cluster of information and biopharmaceutical technologies. By October 17, 2015, the Council of this cluster approved a special "Regulation" which covers the regulating of the monitoring of the cluster development parameters. The form of monitoring of these parameters reflected in the "Regulation" contains a number of indicators that are planned for use in order to actually assess the effectiveness of the cluster (the set of these indicators is very similar to 
the standard for reporting any enterprise, "results of economic activity") and includes data on:

- Shipment of manufactured goods, performance of works and services on their own, thousand rubles. (with the allocation of innovative goods, works, and services from them);

- Revenue from the sale of goods, services rendered and works performed on the foreign market, thousand rubles (and the allocation of innovative goods, works, and services from them);

- Investments in fixed assets, thousand rubles. (with the allocation of machines, equipment, vehicles and household inventory from them);

- Investments in the non-financial part of assets (i.e., the acquisition of patents for inventions, industrial designs. utility models, copyrights, etc.; research costs);

- Research volume - total, thousand rubles. (with the allocation of those carried out as: the head performer and co-performer, as well as jointly with the organizations participating in the pilot territorial cluster, including as: the head performer and coperformer, as well as jointly with foreign organizations, including as: the head performer and co-performer);

- Number of employees who have received retraining and advanced training in the field of management of innovation in educational programs, fully or partially subsidized by the Government Decree No. 188 of March 06, 2013, pers.;

- The payroll of employees that have received retraining and advanced training in the field of management of innovation in educational programs, fully or partially subsidized by the Government Decree No. 188 of March 06, 2013, RUB.;

- The number of employees for whom the average salary was increased due to their retraining and advanced training in the field of innovation management under additional professional education programs fully or partially subsidized by the Decree of the Government of the Russian Federation No. 188 of March 6, 2013, pers.;

- Number of employees for which you were raised average wages because they retraining and advanced training in the field of management of innovative activities on programs of additional professional education, fully or partially subsidized by the government of the Russian Federation No. 188 dated 6 March 2013, at: a) 5\%; b) $5-10 \%$; C) for $10-20 \%$; d) $20-30 \%$; d) $30-50 \%$; e) more than $50 \%$ of people.;

- The average number of employees, people.

It is easy to see that this system of indicators is formed on the basis of the abovementioned set of indicators for monitoring the effectiveness of the provision of federal subsidies. Accordingly, it has all the same disadvantages, namely, insufficient elaboration of the basic logic of evaluating the effectiveness of the object of analysis and the validity of the formation of a set of indicators in its quantitative and qualitative aspects, in order to increase the reliability of the estimates obtained. Thus, the approaches and indicators used today in assessing the effectiveness of federal subsidies to regional cluster structures are not able to provide an understanding of the effectiveness of the cluster as a system object. The causal relationships in the cluster activity, which are largely determined by the nature and intensity of resource-product interactions between its participants, are practically not revealed or analyzed under the current assessment system. This leads to serious shortcomings in the understanding of both the cluster management and federal and regional administrative structures of the true causes of cluster problems, the role of its participants in terms of their real contribution to the overall efficiency of the cluster, the optimal directions and priorities of intra-cluster financing and intracluster resource and product exchanges, as well as other aspects that are important for sound management. In turn, such a circumstance makes it difficult to obtain objective 
assessments, not allowing control structures to effectively monitor the effectiveness of state funding for the creation and development of cluster formations, thereby not contributing to the formation of sound funding directions in this area.

\section{Results and Discussion}

When developing the concept-methods-tools complex in relation to solving the problem of evaluating the effectiveness of cluster structures, it is necessary to follow a systematic approach that makes it possible to "stretch" and link numerous aspects of this process from the general to the particular, from the complex to the simple, and from the system to its elements. An in-depth analysis of the materials associated with the preparation and conduct of such work led us to form the proper logic and stages of the process of creating a system for evaluating the effectiveness of the cluster. In a compressed form, it is shown in figure 1.

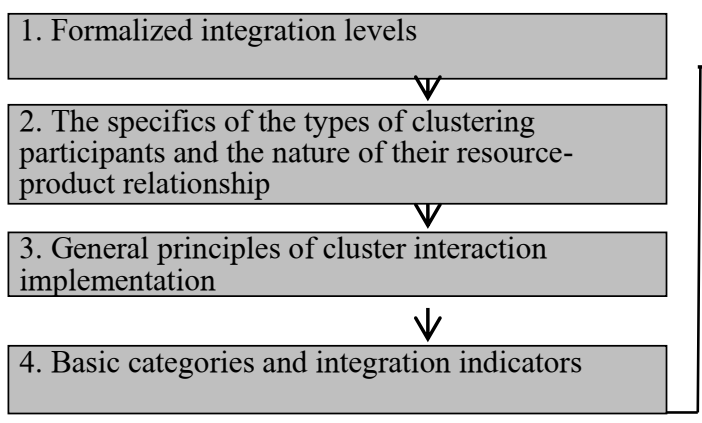

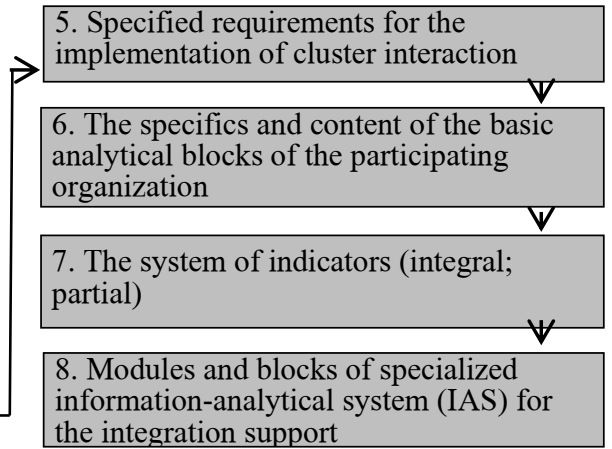

Fig. 1. The logic of the process of forming a system for evaluating the effectiveness of cluster activities.

We will briefly present the essence of each of the stages with a reflection of the main points characteristic of them.

Stage 1. The "multilevel" logic of integration is due to the existing top-down linkage of the three" projections " of innovative integration: a) the specifics of the relationship between the stages of the national innovation cycle, b) the specifics of the integration of various types of participants in the implementation of this cycle, and c) the specifics of the integration of various aspects of the functioning of these participants. This logic is then translated through the development of all the other numerous points in the process stages highlighted in Figure 1.

Stage 2. The specificity of the types of clustering participants and the nature of their resource-product relationship follows from the existing difference in their goals, areas of activity and business processes used. Consideration of these features within the framework of various types of organizations allowed us to identify five basic types of organizations participating in the national innovation cycle: large industrial enterprises, small innovative firms, large universities, academic research institutes, and industry research institutes. For these types of integration participants, an in-depth study of relevant aspects of their activities for integration interaction was conducted, which allowed us to reveal and formalize the complex of their cross-interaction on resources and products.

Stage 3. In order to achieve the task of sharing a common integration ideology by the participants in their work, ensuring the required priorities for their integration, 8 general principles for implementing cluster interaction were formed. 
Stage 4. Due to the multidimensional nature of the cluster activity of the participants and its internal involvement in their main activities, it was then necessary to form a relevant and internally consistent set of basic categories and indicators required (and with a minimum of their number) for the effective translation of the logic of the cluster formation process (based on the previously proposed integration principles). Based on this, basic categories and indicators were proposed, namely, 3 categories and 4 indicators of the state of the cluster as a system, and 2 categories and 5 indicators of the state of an individual participant in clustering as an element of the system).

Stage 5. Based on the presence of the above categories and indicators, 8 specific requirements for the implementation of cluster interaction were subsequently formalized to project the chosen logic on the real situation of the activity and determine the specifics of the subsequent activity of the participants in this process (both in the implementation of their evaluation and analytical functions, and in terms of their management decisions):

Stage 6. Based on all the previous aspects, in order to obtain a comprehensive understanding of the state of the organization participating in the cluster initiative, the structure and relationship of the 4 main analytical blocks used to clarify the effectiveness of the participant's activities are developed. These blocks are designed to reflect the nature of any economic entity through a closed relationship of four projections of its activities (finance-resources/processes-products-final results). Each analytical block consists of a logical sum of two aspects: the potential of this block and the realization of this potential.

Stage 7. Further work was associated with the selection of integral and partial indicators that translate the logic of assessing the state of cluster activity, reflected in the previous steps. Based on this task, a 6-level system of indicators relevant to our plan was created. Through 5 higher levels (levels of integral indicators) it reflects the universal part of its activity that is typical for any type of cluster, and through the last level (the level of private indicators) - the specifics of a particular cluster, primarily related to the composition of its participating organizations.

Stage 8. To support and automate the functions of collecting, storing, analyzing, evaluating and predicting data from the arrays obtained during the cluster operation, in order to facilitate the further adoption of informed management decisions of the cluster as a whole and its participants, the main modules of the specialized information-analytical system (IAS) to support the creation and development of clusters have been developed. This IAS translates the logic described above, and is designed to reveal as much as possible the existing cause-and-effect relationships in the multi-level and multidimensional activities and interaction of the organizations participating in the cluster. This circumstance contributes to obtaining an adequate picture of what is happening and thus to the effective management of the cluster both at the stage of its formation and in the process of its further development.

In the end, the achieved results of each of the implemented stages, combined with the logic described above, allowed us to form a well-founded scientific and methodological complex that can solve the problem of supporting territorial economic clustering $[15,16]$.

\section{Conclusions}

A comprehensive analysis of the conditions and specifics of ensuring the sustainable development of territories based on the intensification of the domestic innovation cycle and the clustering of the economy has convincingly demonstrated that to manage these processes, the right approaches and mechanisms are needed that are relevant to the emerging national and regional conditions. If there are currently a set of specific mechanisms that implement the tasks of state financing (subsidizing) the processes of creating and supporting the activities of clusters, the general approaches and reporting 
indicators used are not able to fully translate the understanding of the cluster's activities as a system object. The cause-and-effect chains in the work of cluster participants, formed by the nature and intensity of their interactions on resources and products, are very poorly revealed with the evaluation system used and are not properly analyzed. This determines the shortcomings of understanding both the top management of the cluster and the authorities of the real causes of the cluster problems, the role of the participating organizations in terms of their actual contribution to the overall performance of the cluster, adequate directions and priorities of resource and product exchanges in the cluster, as well as many other important points for effective management. As a result, this circumstance prevents obtaining objective assessments of cluster activities, makes it difficult for competent monitoring of the effectiveness of state subsidies to cluster initiatives by the control bodies, thereby damaging the possibility of forming the right directions for financing the clustering of the economy.

The solution to the problem of achieving sustainable development of territories should be carried out today on the basis of the already accumulated positive experience both in terms of creating and applying the conceptual apparatus, and in the methodological and instrumental part. As world practice shows, one of the most effective ways to solve this problem is to assist in the formation and development of territorial cluster structures. In turn, the creation of a conceptual and methodological apparatus in relation to the issues of effective economic clustering can significantly advance the solution of the above tasks.

The work carried out made it possible to form a set of conceptual and methodologicalinstrumental provisions that are scientifically based and adequate to the domestic economic conditions, allowing to increase the efficiency of the process of creating and further developing cluster structures. This complex contains various aspects of philosophical, model, mathematical, information and analytical nature, linked by a single logic within the framework of the set goals. The development of the complex presented above allows, in the end, to create a favorable environment for domestic clusters, to evaluate the effectiveness of their activities, to form and adjust their development strategies. Working out the proposed approaches to the integration of organizations (with the subsequent scaling of the accumulated experience at the regional and national level) can become a significant factor in promoting the growth of the competitiveness of territories and the domestic economy as a whole.

\section{References}

1. M. Porter, Regional Studies, 549 (2003)

2. C. Ketels, Economy and Society, 269 (2013)

3. E. Kutsenko, Foresight Russia, 32 (2015)

4. G. Lindqvist, C. Ketels, Ö. Sölvell, Ivory Tower Publishers (2013)

5. S. G. Tyaglov, P. A. Krasnokutsky, Vestnik REU, 114 (2011)

6. P. Cooke, Research Policy, 1128 (2005)

7. R. P. Kiselyov, Vestnik of RSEU, 47 (2016)

8. Center of Innovation, http://www.center-inno.ru/

9. V. V. Kholodkova, Finance and Credit, 95 (2018)

10. Methodological recommendations for the implementation of cluster policy in the constituent entities of the Russian Federation (2008) http://www.economy.gov.ru/

11. Order of the Ministry of Economic Development of the Russian Federation "On the priority project of the Ministry of Economic Development of Russia" Development of 
innovative clusters - leaders of investment attractiveness of the world level" (2016) https://docs.cntd.ru/

12. Resolution of the Government of the Novosibirsk region "On approval of the Concept of cluster policy of the Novosibirsk region" (2015) https://docs.cntd.ru/

13. Resolution of the Government of the Novosibirsk region "On approval of the program of state support for the development of the Innovative Cluster of Information and Biopharmaceutical Technologies of the Novosibirsk Region for the period 2013-2017" (2013) https://docs.cntd.ru/

14. Development strategy of the Scientific and production cluster "Siberian science polis" (2016) https://www.hse.ru/

15. O. Lyamzin, Proc. of International scientific-technical conference "Actual problems of electronic instrument engineering (APEIE-2016)". Russia, Novosibirsk, October 3-6, 2016, 1, 3, 263 (2018)

16. O. Lyamzin, Journal of Physics: Conference Series, 1353, 012130 (2019) 